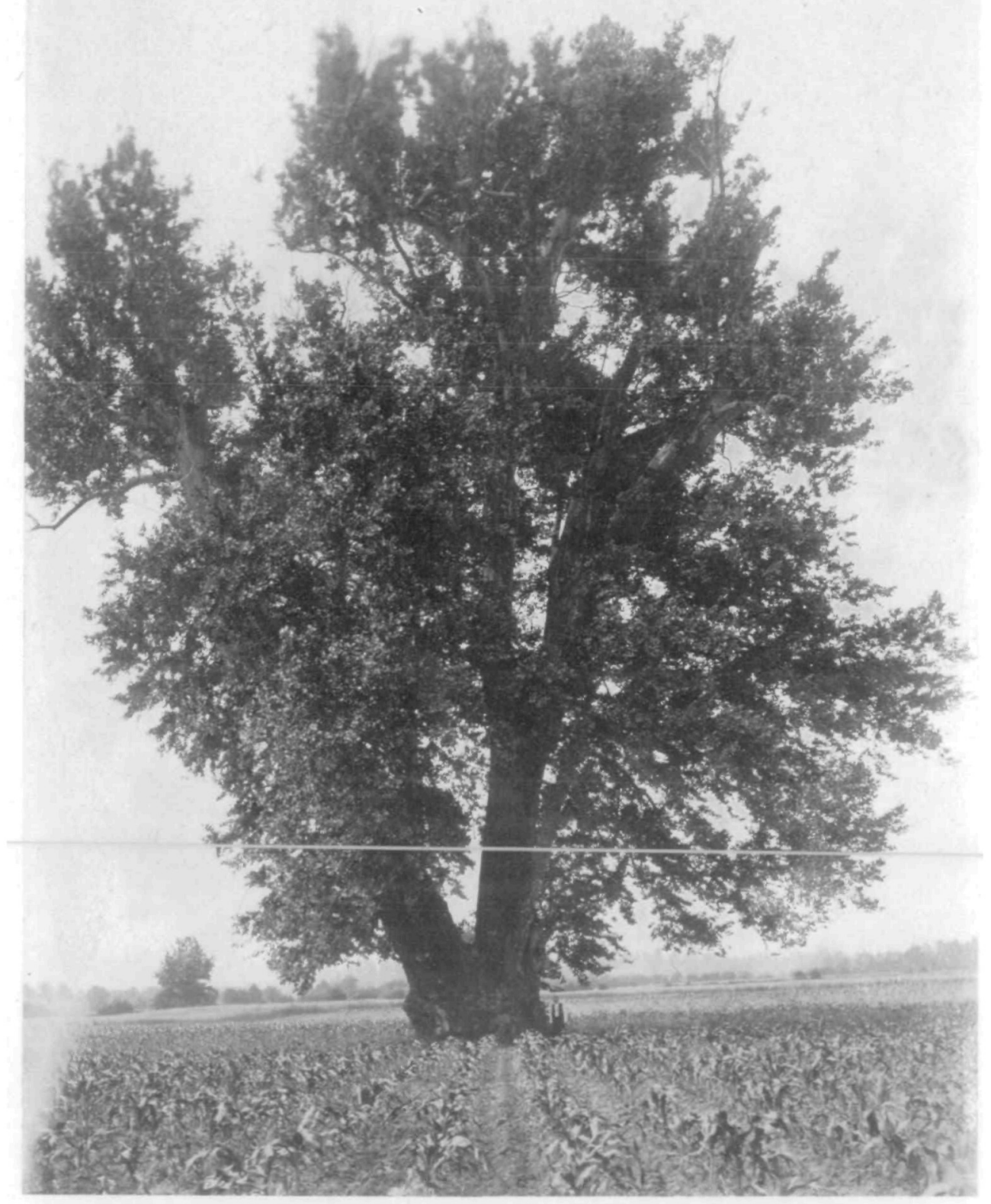

LARGEST TREE FOUND BY THIS ASSOCIATION

Sycamore, buttonwood or plane tree (Plalanus occidentalis) near Worthington, Ind, by a big margin the largest tree submitted in response to the American Genetic Association's offer of prizes for photographs. It is 42 feet 3 inches in circumference and about 140 feet high. Barring conifers, among which the California Sequoias defy competition, the sycamore probably reaches a larger size than any other tree in North America; and although reports of bigger trees are from time to time made, this association has been unable to get authentic record of any specimen which equals the Worthington tree in size. Its age is unknown, but "oldest inhabitants" declare it has not increased perceptibly in size in the last sixty years. (Frontispiece.)

[See "Photographs of Large Trees," p. 407.] 


\title{
COLOR IN COCKER SPANIELS
}

\section{Study of Eighty-nine Matings Shows Numerous Correlations in Color and Indicates That Inheritance Is Along Same Lines as in Pointer Dogs-Analogies in Other Breeds}

\author{
W. M. BARROWS \\ Assistant Professor of Zoology, Ohio State University, Columbus, Ohio. \\ and \\ J. McI. Phillips \\ Director of Pasteur Institute; Owner, Scioto Kennels; Columbus, Ohio.
}

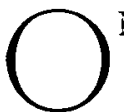

$\mathrm{NE}$ of the few serious pieces of research work on the inheritance of coat color in dogs is that reported in this journal last year by C. C. Little. He showed ${ }^{1}$ that in Pointers, black, brown (liver), and yellow (lemon, orange and tan) are inherited in true Mendelian fashion, segregation showing the colors to be due to two factors.

Little's data were from the American Kennel Club records. The authors of this article have utilized private records, ${ }^{2}$ comprising eighty-nine matings; in each case the record includes the names and colors of the grandparents, parents and offspring. With this material, we tested Little's conclusions, to see to what extent, if any, they hold good for Cocker Spaniel dogs.

It is, perhaps, worth emphasizing that our records include every pup born in a litter, whether these dogs were later registered or not. Dogs are included here that are in some cases considered undesirable from the breeders standpoint, and would not ordinarily be shown or recorded. To the genetist, this is naturally a distinct advantage, and makes private records rather more trustworthy than stud- or herd-book records on which most investigators are obliged to rely. And as we were personally acquainted with the owners of the dogs, we were able to take every possible precaution to ensure accuracy in the records and descriptions of the colors. For these reasons we feel that, although the total number of matings studied is not large, the results are worthy of confidence.

The colors of Cocker Spaniels are ordinarily spoken of as blacks, livers, reds, and lemons, the reds and lemons corresponding to the yellow colors of Pointers. It is well known that livers may occur in two shades, one a dark chestnut, the other a lighter, more faded liver color. The reds vary from mahogany to lemon, through the red and orange shades. The colors known as lemons are difficult to distinguish from the reds, in fact a good many reds are registered in the Kennel Records as lemon, and some lemons as red. The lemon color may be a brilliant lemon or dull buff, almost without lustre. In distinguishing red and lemon the final test is the color of the offspring when the doubtful animal is mated with a recognized lemon. As a rule a lemon pup is cream or white at birth, and becomes darker with age, while a red shows considerable color at birth.

Our method in attempting to determine whether or not the scheme suggested by Little would hold for Cocker Spaniels was as follows: a table was constructed to show what results might be expected when a dog of any color type was crossed with a bitch of any color type. This arrangement is re-

\footnotetext{
${ }^{1}$ Coat Color in Pointer Dogs, Journal of Heredity, Vol. V, no. 6, pp. 244-248; June, 1914.

2 The largest number of records are from the Scioto Kennels. Others were furnished by $O$. B. Hark, Mrs. M. G. Faber, Mrs. Bonner, Mrs. Walls, F. E. Curtis and Mrs. F. J. Frank. We take this opportunity to thank them for their interest and help in this study.
} 


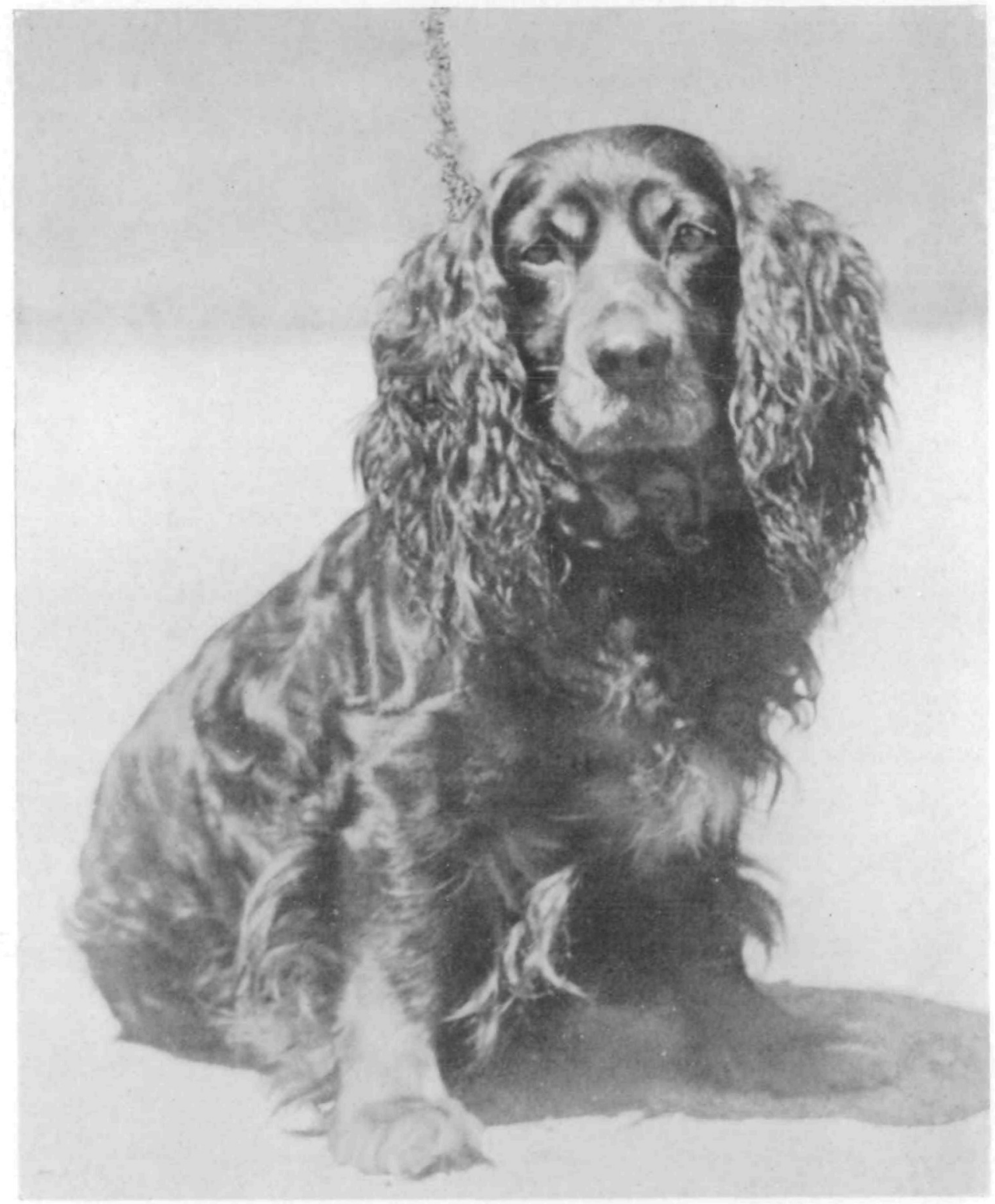

\section{CHAMPION FRANZA}

A good specimen of the black and tan bicolor Cocker Spaniel, with typical markings, owned by the Daffodil Farm Kennels (Mrs. F. J. Frank). From a genetic point of view, this color combination is to be looked on as due to a pattern-factor which allows a lighter (lemon) color to show on certain well-defined areas of the body. The bicolor combination is certainly recessive, so when two black and tan animals are mated, they should always produce bicolor spotted dogs, never any solid-colored ones. (Fig. 1.) 


\begin{tabular}{|c|c|c|c|c|c|c|c|c|c|c|c|}
\hline 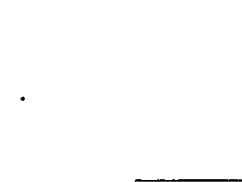 & 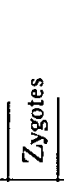 & $\mid$ & $\begin{array}{c}\overrightarrow{0} \\
\text { Õ } \\
\vec{U} \\
\text { BLACK }\end{array}$ & 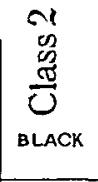 & 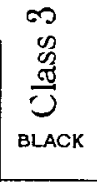 & $\left|\begin{array}{c}\vec{v} \\
n \\
\tilde{\sigma} \\
\vec{U} \\
\text { BLACK }\end{array}\right|$ & $\begin{array}{c}10 \\
0 \\
0 \\
0 \\
0 \\
\text { LIVER }\end{array}$ & $\begin{array}{c}\infty \\
0 \\
0 \\
0 \\
0 \\
\text { LIVER }\end{array}$ & $\underset{\text { RED }}{\infty}$ & $\begin{array}{c}\infty \\
0 \\
2 \\
\pi \\
0 \\
0 \\
\text { RED }\end{array}$ & 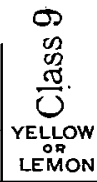 \\
\hline Zygotes & & & $\mathrm{BE} \quad \mathrm{BE}$ & $\begin{array}{lll}\text { BE } \\
\end{array}$ & $\mathrm{BE} \quad \mathrm{bE}$ & BE be & bE $\quad$ bE & be $\quad b E$ & $\mathrm{Be} \quad \mathrm{Be}$ & $\mathrm{Be}$ be & be be \\
\hline Gametes & & & \begin{tabular}{|l|l|}
$\mathrm{BE}$ & $\mathrm{BE}$ \\
\end{tabular} & \begin{tabular}{|l|l|}
$\mathrm{BE}$ & $\mathrm{Be}$ \\
\end{tabular} & \begin{tabular}{l|l|}
$\mathrm{BE}$ & $\mathrm{bE}$ \\
\end{tabular} & 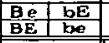 & \begin{tabular}{|l|l|}
$\mathrm{bE}$ & $\mathrm{bE}$ \\
\end{tabular} & \begin{tabular}{|l|l|} 
be & $\mathrm{bE}$ \\
\end{tabular} & \begin{tabular}{l|l}
$\mathrm{Be}$ & $\mathrm{Be}$ \\
\end{tabular} & \begin{tabular}{|l|l|} 
Be & be \\
\end{tabular} & \begin{tabular}{|l|l|} 
be & be \\
\end{tabular} \\
\hline Class 1 BLACK & $\begin{array}{l}\mathrm{BE} \\
\mathrm{BE}\end{array}$ & \begin{tabular}{|l||}
$\mathrm{BE}$ \\
$\mathrm{BE}$ \\
\end{tabular} & $\mathbf{B}$ & $\mathbf{B}$ & B & B & B & $\mathbf{B}$ & B & $\mathbf{B}$ & B \\
\hline Class 2 BLACK & \begin{tabular}{|l|}
$\mathrm{BE}$ \\
$\mathrm{Be}$ \\
\end{tabular} & \begin{tabular}{|l|}
$\mathrm{BE}$ \\
$\mathrm{Be}$ \\
\end{tabular} & & $\begin{array}{l}3 B \\
1 R\end{array}$ & B & $\begin{array}{l}3 \mathrm{~B} \\
1 \mathrm{R} \\
\end{array}$ & B & $\begin{array}{l}3 \mathrm{~B} \\
1 \mathrm{R} \\
\end{array}$ & $\begin{array}{l}\mathrm{IB} \\
\mathrm{IR}\end{array}$ & $\begin{array}{l}\text { 1B } \\
1 \mathrm{R}\end{array}$ & $\begin{array}{l}1 B \\
1 R\end{array}$ \\
\hline Class 3 вLACK & \begin{tabular}{|l|}
$\mathrm{BE}$ \\
$\mathrm{bE}$
\end{tabular} & \begin{tabular}{|l|}
$\mathrm{BE}$ \\
$\mathrm{bE}$ \\
\end{tabular} & & & $\begin{array}{l}3 B \\
1 L\end{array}$ & $\begin{array}{l}\text { 3B } \\
\text { 1L }\end{array}$ & $\begin{array}{l}\text { 1B } \\
\text { IL }\end{array}$ & $\begin{array}{l}\mathbf{1 B} \\
1 \mathrm{~L}\end{array}$ & B & $\begin{array}{l}\text { 3B } \\
\mathbf{L} .\end{array}$ & $\begin{array}{l}\text { IB } \\
\text { IL }\end{array}$ \\
\hline Class 4 вLACK & \begin{tabular}{l|}
$\mathrm{BE}$ \\
be
\end{tabular} & \begin{tabular}{|l|l|}
$B E$ & Be \\
$\mathrm{LE}$ & $\mathrm{be}$ \\
\end{tabular} & & & & $\begin{array}{|ll|}9 \mathrm{~B} & 3 \mathrm{R} \\
3 \mathrm{~L} & 1 \mathrm{Y} \\
\end{array}$ & $\begin{array}{l}1 \mathrm{~B} \\
1 \mathrm{~L}\end{array}$ & \begin{tabular}{|ll}
$3 \mathrm{~B}$ & $1 \mathrm{R}$ \\
$3 \mathrm{~L}$ & $1 \mathrm{Y}$ \\
\end{tabular} & $\begin{array}{l}\text { 1B } \\
1 \mathrm{R} \\
\end{array}$ & $\begin{array}{|ll|}3 \mathrm{~B} & 3 \mathrm{R} \\
1 \mathrm{~L} & 1 \mathrm{Y} \\
\end{array}$ & $\begin{array}{ll}1 \mathrm{~B} & 1 \mathrm{R} \\
1 \mathrm{~L} & 1 \mathrm{Y} \\
\end{array}$ \\
\hline Class 5 LIVER & \begin{tabular}{|l|}
$b E$ \\
$b E$ \\
\end{tabular} & \begin{tabular}{|l|}
$\mathrm{bE}$ \\
$\mathrm{bE}$ \\
\end{tabular} & & & & & L & $\mathbf{L}$ & B & \begin{tabular}{|l||}
$1 \mathrm{~B}$ \\
$\mathrm{IL}$
\end{tabular} & $\mathbf{L}$ \\
\hline Class 6 LIVER & $\begin{array}{l}\text { be } \\
\mathrm{bE} \\
\end{array}$ & \begin{tabular}{|l|} 
be \\
$\mathrm{bE}$ \\
\end{tabular} & & & & & & $\begin{array}{l}3 \mathrm{~L} \\
1 \mathrm{Y} \\
\end{array}$ & $\begin{array}{l}\text { 1B } \\
1 \mathrm{R} \\
\end{array}$ & $\begin{array}{|ll|}\mathrm{B} & \mathrm{1R} \\
1 \mathrm{~L} & \mathrm{YY} \\
\end{array}$ & $\begin{array}{l}\mathrm{L} \\
1 \mathrm{Y} \\
\end{array}$ \\
\hline Class 7 RED & \begin{tabular}{ll|}
$\mathrm{Be}$ \\
$\mathrm{Be}$ \\
\end{tabular} & \begin{tabular}{|l|}
$\mathrm{Be}$ \\
$\mathrm{Be}$ \\
\end{tabular} & & & & & & & $\mathbf{R}$ & $\mathbf{R}$ & $\mathbf{R}$ \\
\hline Class 8 RED & \begin{tabular}{|l|}
$\mathrm{Be}$ \\
$\mathrm{Be}$ \\
\end{tabular} & \begin{tabular}{|l} 
be \\
be \\
\end{tabular} & & & & & & & & $\begin{array}{l}\mathrm{R} \\
1 \mathrm{Y} \\
\end{array}$ & $\begin{array}{l}1 \mathrm{R} \\
1 \mathrm{Y} \\
\end{array}$ \\
\hline Class $9 \begin{array}{l}\text { YELLOW } \\
\text { LEMONON }\end{array}$ & \begin{tabular}{|l|} 
be \\
be
\end{tabular} & \begin{tabular}{|l} 
be \\
be
\end{tabular} & & & & & & & & & $\mathbf{Y}$ \\
\hline
\end{tabular}

BREEDING COCKER SPANIELS BY ALGEBRA

Table I, for determination of average results to be obtained by interbreeding the different colors of Cocker Spaniels. To use table, first determine the class to which each dog belongs and then trace the columns to the square in which they meet. Here the colors to be expected and their average relative numbers will be found. A single large letter in the square indicates that the entire litter will be of that color. $B=$ black, $R=$ red, $L=$ li ver or chocolate, and $\mathrm{Y}=$ lemon. The class to which a given dog belongs can in some cases be determined by a careful analysis of the pedigree and its color, in others by the results of a previous mating. Or the procedure may be reversed. To determine the class of any animal examine a litter the result of mating with another animal, preferably of another color. The determination of the class of two black parents is the most difficult and several other matings may be neceзsary bziore an accura te determination is made.

produced herewith as Table I. A glance at the table will show that, using Little's formulae in which BE represents the essentials of the black color type, there will be four possible kinds of black dogs. These are $\mathrm{BE} \mathrm{BE}$, $\mathrm{BE} \mathrm{Be}, \mathrm{BE} \mathrm{bE}, \mathrm{BE}$ be, and will be mentioned as classes $1,2,3$, and 4 respectively. So far as we have been able to learn there is no way to determine accurately, from the external appearance, to which class a given black dog may belong. However, rusty black dogs do not belong to class 1 . Two classes of livers will be noted, $\mathrm{bE} \mathrm{bE}$, and $\mathrm{bE}$ be, classes 5 and 6 . Two kinds of reds $\mathrm{Be} \mathrm{Be}$, and $\mathrm{Be}$ be, classes 7 and 8 , are found; but only one kind of lemon, be be, class 9 , can occur.
The red colors of Cockers seem to differ from the yellows of Pointers in being usually very clearly red, not yellow. For convenience we will hereafter speak of the different color types of dogs by giving their class numbers as they are shown in the table. Table I was next used by taking the individual pedigrees and determining from them the class to which each dog belongs; for example, Lucky is known to be of class 3, that is, he has the formula $\mathrm{BE} \mathrm{Be}$. He should be found to have the same formula judging by his offspring no matter to what color of bitch he was mated. In this particular case we have found in the records that Lucky belongs to class 3 . We have records of nine of his matings, five times to females 


\begin{tabular}{|c|c|c|c|c|c|c|c|c|c|}
\hline & 1 & 2 & 3 & 4 & 5 & 6 & 7 & 8 & 9 \\
\hline 1 & & $11 \mathrm{~B}(2)$ & $11 \mathrm{~B}(1)$ & & & & $\begin{array}{r}11 \mathrm{~B}(2) \\
7\end{array}$ & \begin{tabular}{|l|}
$10 B(2)$ \\
$B(1)$
\end{tabular} & \\
\hline 2 & & & $8 \mathrm{~B}(1)$ & ${ }_{5 \mathrm{P}}^{10 \mathrm{~B}}(2)$ & & & $\begin{array}{l}7 \mathrm{~B}_{(4)} \\
6 \mathrm{R}\end{array}$ & $\begin{array}{l}19 B_{(7)} \\
13 R^{\prime}\end{array}$ & \\
\hline 3 & & & \begin{tabular}{|c|}
$36 \mathrm{~B}$ \\
$10 \mathrm{~B}$ \\
$3 \mathrm{~L}(2)$
\end{tabular} & $(10)$ & & & $23 \mathrm{~B}(4)$ & \begin{tabular}{|c|}
$10 B_{(3)}$ \\
$3 L^{\prime}$
\end{tabular} & \\
\hline 4 & & & & $\begin{array}{l}3 \mathbf{B}_{(1)} \\
1 \mathbf{R}^{(1)}\end{array}$ & & & $\begin{array}{l}3 \mathrm{~B} \\
2 \mathrm{R}\end{array}$ & 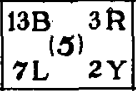 & \\
\hline 5 & & & & & & & $8 \mathrm{~B}(1)$ & & \\
\hline 6 & & & : & & & $\begin{array}{l}3 \mathrm{~L}(1) \\
1 \mathrm{Y}(1)\end{array}$ & $\begin{array}{l}9 \mathrm{~B}_{(2)} \\
5 \mathrm{~B}\end{array}$ & $\begin{array}{|ll|}3 & \mathrm{~B} \\
2 & \mathrm{~L}(1) \\
2 & \mathrm{R} \\
\end{array}$ & \\
\hline 7 & & & & & & & $7 \mathrm{R}(\mathbf{1})$ & $39 R(10)$ & \\
\hline 8 & & & & & & & & \begin{tabular}{r|}
$18 \mathrm{R}_{(3)}$ \\
\end{tabular} & $\begin{array}{l}3 R_{(1)} \\
1 Y^{(1)}\end{array}$ \\
\hline 9 & & & & & & & & & \\
\hline
\end{tabular}

HOW EXPECTATION WAS FULFILLED

Table II shows the results of crossing various types of Cocker Spaniels, made up from the records of matings furnished to the authors, and based on Table I. Only those matings are here shown in which the formula (class) of each parent is known from two or more matings, $\mathrm{B}=$ black, $\mathrm{R}=\mathrm{red}, \mathrm{L}=$ liver, $\mathrm{Y}=$ lemon or yellow. Figures in parenthesis indicate the number litters.

of class 3 or 4 , three times to class 7 , and once to class 8 . The results of the first five matings gave thirty-six blacks and twelve livers, an exact agreement with the table. The next three matings, (classes 3 by 7 ) yielded fifteen black pups. The last mentioned cross ( 3 by 8 ) gave four blacks and one liver. In this list each of the red bitches of class 7 was mated more than once and in each mating behaved as a class 7 should, no discordant results being obtained.

We have now double-checked each individual which occurs in two or more matings, and find that the records show the actual existence of each of the nine classes represented, and that with two exceptions the results accord with those expected from Table I. Table II shows part of our actual records.

A comparison of this table with Table I will show that the results agree very closely with those expected. The litter shown as a result of the mating of class 4 by class 4 is placed here because the sire when mated to a red of class 8 gave four blacks and one liver. The only possible arrangement of these litters is to class one as 4 by 4 and the other as 4 by 8 . This is, perhaps, the most questionable case given in the table. We have no records of the matings of liver to liver. But Rev. T. Moore-Smith, an extensive breeder of Irish Water Spaniels, writes us that they always breed true in his kennel, and so their formula is probably $\mathrm{bE} b E$, and they represent the mating 5 by 5 .

The litter shown as a result of two livers $(6$ by 6$)$ is a litter of English Water Spaniels. However, there is probably very little objection to its inclusion since at one time both English and Irish Water Spaniels were freely bred with the Cocker Spaniels.

Out of eighty-nine litters there were two which could not be fitted into the table. A red dog of class 8 was sup- 


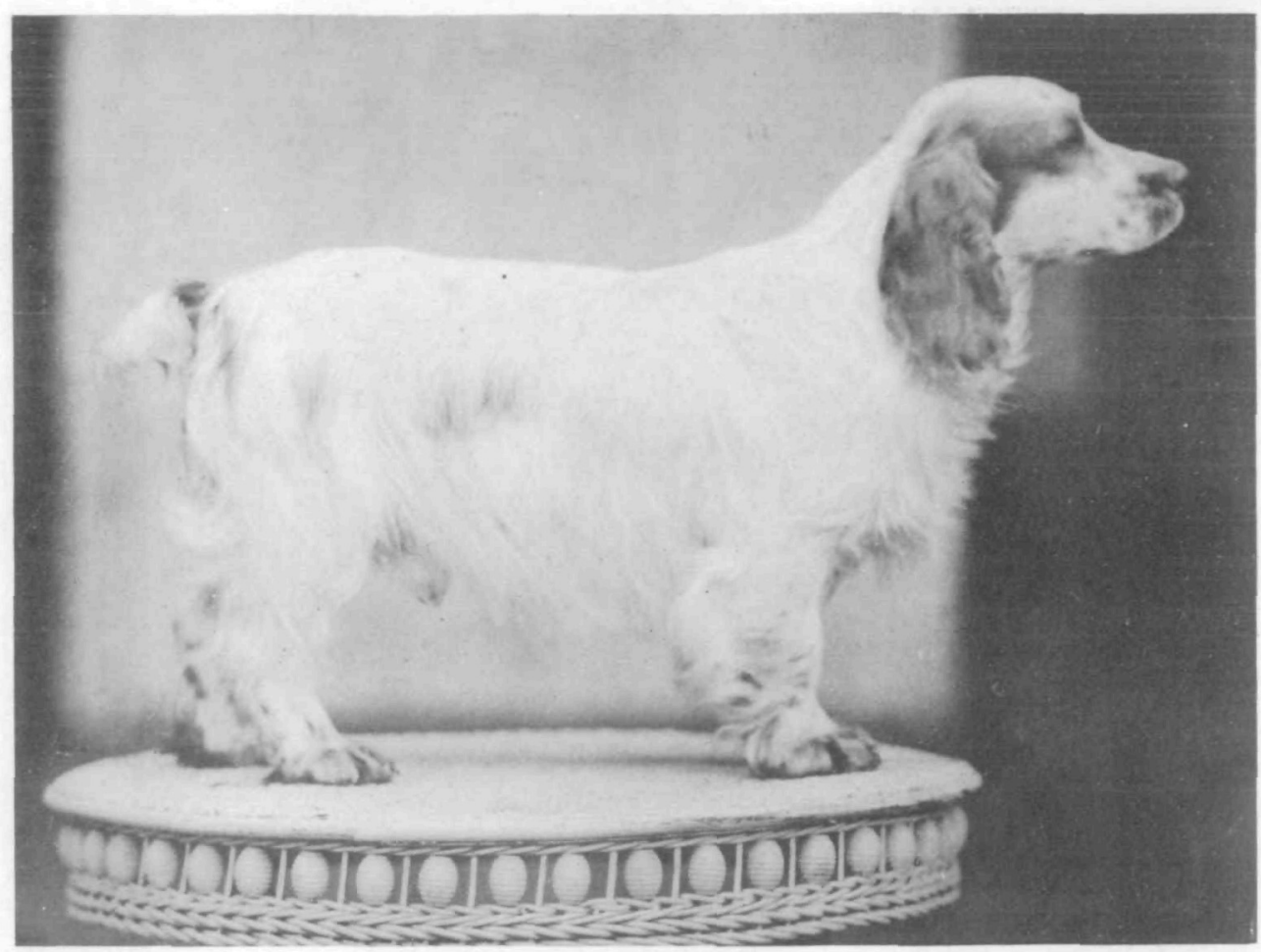

\section{CHAMPION MEPAL'S 'THE JUDGE}

By examination of pedigree and the results of previous matings, it is known that this red and white Cocker Spaniel has the formula $\mathrm{Be} \mathrm{Be}$, and also carries the recessive bicolor factor. On the basis of this information, it will henceforth be possible to predict with fair accuracy the kind of pups that will be produced from his mating with any female of known genetic makeup. If the latter is red, yellow or lemon, all the pups should be, without exception, red. Photograph from H. K. Bloodgood's Mepal Kennels. (Fig. 2.)

posedly mated to one of class 7 . The litter resulting contained one red, one liver, and one lemon. It was recognized at once that for two reds to produce anything but red or lemon was decidedly out of the ordinary. Our data shows that in seventeen matings of red by red, eighty-three red or lemon pups resulted. This one exception, then, cannot well offset such clear evidence that red by red gives red or lemon especially when one considers the difficulty of keeping these active little dogs confined when the breeding period lasts from five to twelve days.

The second exception occurs in the cross of a black of class 2 with a black which we may call Bob. The first cross yielded six blacks. The second time that this mating was made its result was four blacks and one red. Taken by themselves these two litters are not necessarily incompatible. Two other matings with Bob show conclusively that he is class 1 . Hence the second litter mentioned above was probably not sired by Bob. In this case whelping occurred several days ahead of time. This, taken with some other evidence shows conclusively that the mating was not correctly recorded. The conclusion to be drawn from a comparison of the two tables is, that in Cocker Spaniels the clear colors are inherited in typical Mendelian fashion and can be accurately predicted when the type of the parent is known and due regard is given to the vagaries of chance in fertilization. 


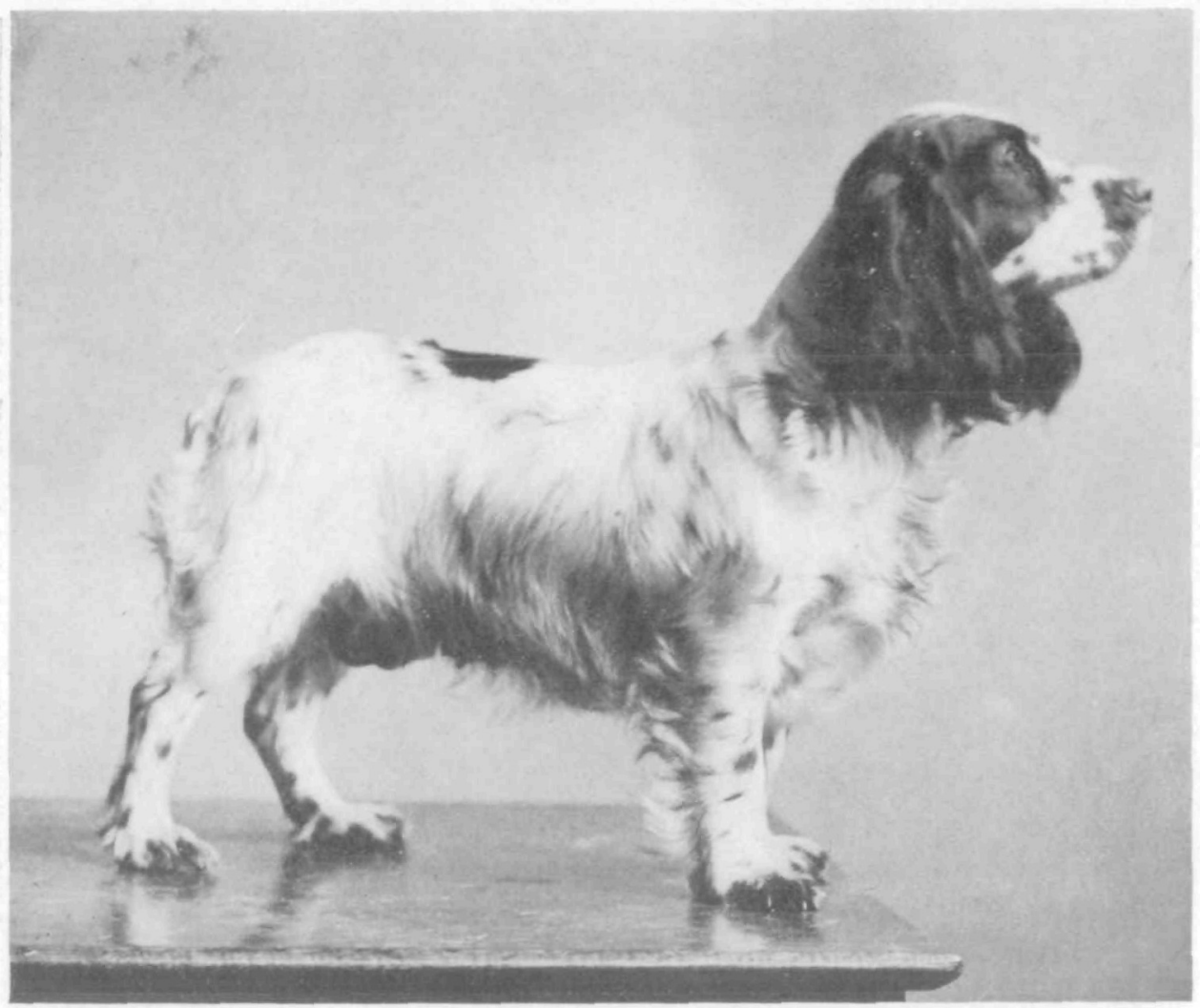

\section{CHAMPION SCIOTO TAD POLE}

Black and white Cocker Spaniel bitch owned by the Scioto Kennels (Dr. J. McI. Phillips). Her formula has been ascertained to be $\mathrm{BE} B$, and reference to the table published on another page makes it easy to predict the results of mating her with any kind of dog of the same breed, whose formula is likewise known. Black is a harder color to work with than any other in Cocker Spaniels, because research shows that there are four kinds of black which look alike but breed differently. Furthermore, the presence of white (or "spotting") adds another complication, because it is apparently due to a number of separate factors, which usually act as a unit. As the spotting is usually dominant, we can say at a glance that the pups of this bitch will probably all be spotted, but whether they will be black and white or red and white can only be predicted by complete knowledge of the genetic makeup of the dog with which she will be mated. (Fig. 3.)

\section{DILLTE COLORS}

There occurs occasionally among Cockers a dilute color (dilute black), known as blue, and also individuals which appear to be white. Fig. 6 shows Simcoe Purity, one of these whites, owned by Frank E. Curtis. Simcoe Purity was from a solid black sire and a solid red dam. In the same litter were two red females, Doris and Betty. Mr. Curtis describes the productions of whites and blues from these in these words: "I bred Purity to his two litter sisters Doris and Betty and never failed to get one or two pure white pups in every litter, and with one exception they were always strong and healthy. I usually had in each litter what might be called a blue pup (in my opinion a miserable color) the others were either red or black. When Purity was in stud he was bred to outside bitches, but never threw a pure white pup." "Purity's eyes, nose, and foot pads were black." 


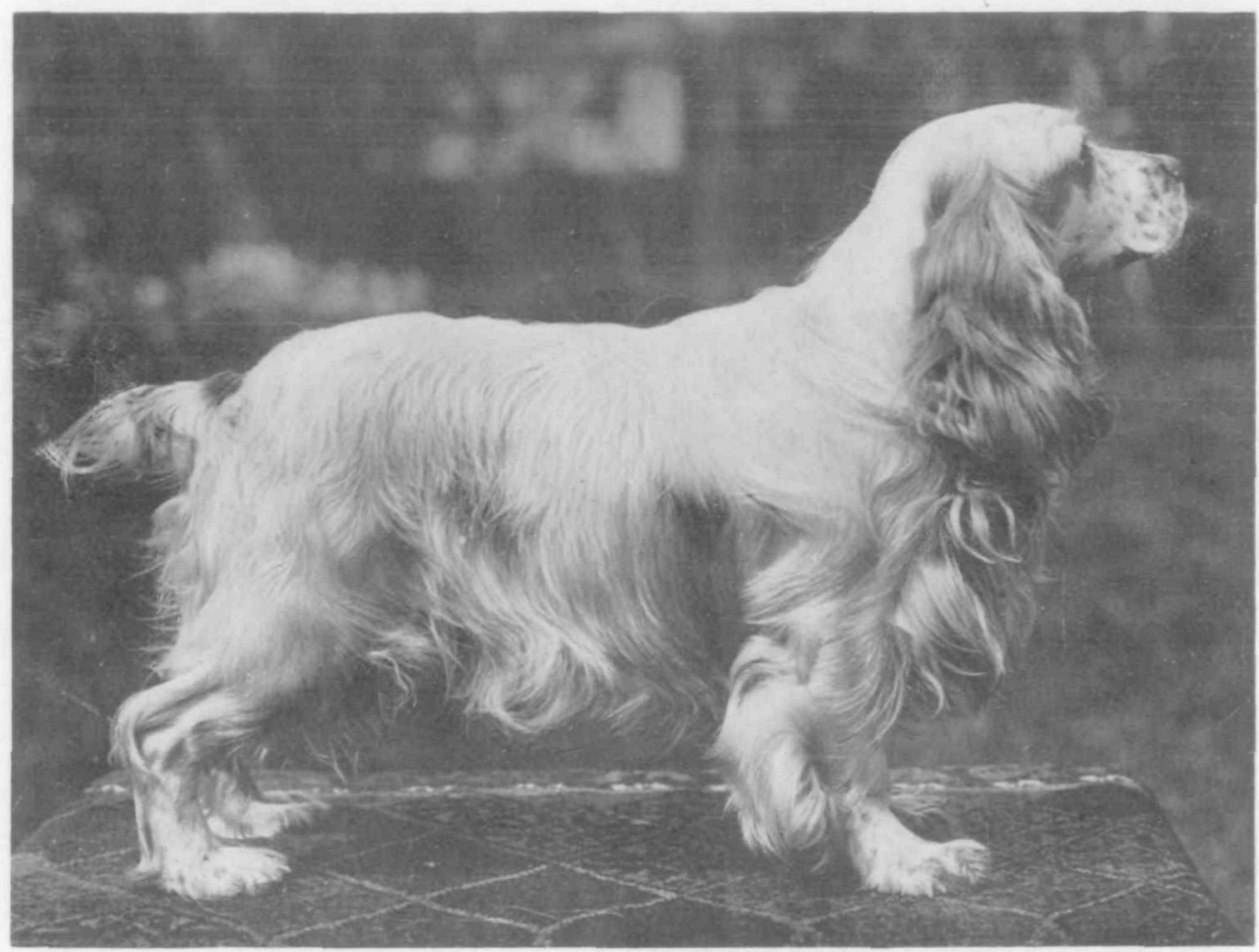

\section{CHAMPION SCIOTO PHILIP}

Red and white Cocker Spaniel owned by Dr. J. McI. Phillips; his formula is known to be Be be, and he also carries the bicolor factor. Mated with a black female of pure ancestry, all the pups will be black; mated with a red female of pure ancestry, all the pups will be red; while if the mating is with a female that likewise carries the bicolor factor, all the pups will be bicolor. Results of the mating can be predicted with fair accuracy in the case of a mating with any other type of Cocker Spaniel. (Fig. 4.)

This single pedigree is mentioned to show that dilute colors do occur, and that the dilution factor is a recessive and becomes visible only occasionally or as a result of inbreeding in a strain which carries it. It seems improbable that the whites mentioned are true albinos. We are inclined to consider them as dilute lemon. Dilute reds are cream in color. The photograph of Simcoe Purity shows a slight darkening which might be due to yellow, invisible to the eve, but accentuated by the photographic plate.

\section{ROAN PATTERN}

A mixture of white hairs with the normally colored ones gives rise to the roan colors, of which our records show two litters. In the first a blue roan (black with white hairs) mated with a red spotted gave three black and white pups and two red roans, in the second another blue roan mated with red spotted gave three blue roans, and one liver roan. This is probably a 3 by 8 mating, the roan animal being homozygous for the roan factor. The roan pattern factor is evidently dominant.

\section{SPOTTING}

Spotting occurs in two general types, which we shall speak of as ordinary spotting and bicolor spotting. The ordinary spotting is the common condition in which the dog is more or less irregularly marked. with patches of black and white, red and white, lemon and white, or liver and white. The spots vary from small breast or face 


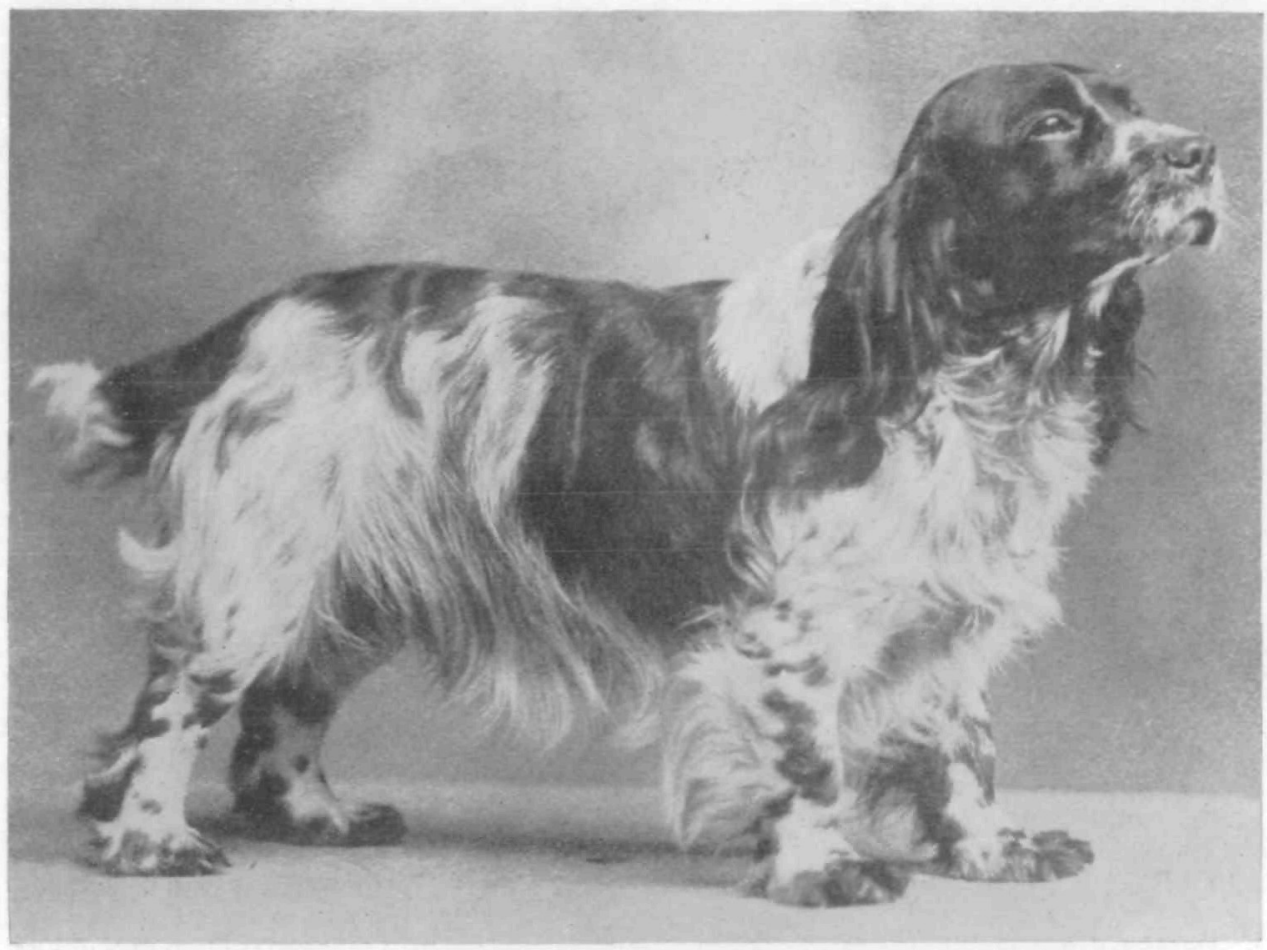

\section{CHAMPION LUCKY}

Black and white Cocker Spaniel owned by Pleasant Hill Kennels (O. B. Hark). Investigation of his pedigree showed that his formula was $\mathrm{BE}$ Be (class 3). According to theory, when he is mated with a female of similar genetic makeup, the pups should be $75 \%$ black and $25 \%$ liver. Five matings of this sort were recorded, and it was found that they resulted in thirty-six blacks and twelve livers-an exact agreement with the calculated total. By the law of chance, the results will not always come so close, when a small number is concerned; but it is evident that much of the uncertainty surrounding dog-breeding will be removed by the use of such Mendelian calculations as are described in the accompanying article. (Fig. 5.)

splashes to the condition in which the dog is largely white, with a few scattered marks of color. The method of inheritance is shown in the accompanying summary of our records.
Spotting is dominant in this case as in most cases so far studied, and is apparently due to multiple factors, which in their most perfect development act as a single factor. The irregularities

Table III

\begin{tabular}{|c|c|c|c|}
\hline Mating & $\begin{array}{l}\text { All Individuals } \\
\text { Spotted }\end{array}$ & $\begin{array}{l}\text { Individuals Mixed } \\
\text { Spotted and Solid }\end{array}$ & $\begin{array}{c}\text { All Individuals } \\
\text { Solid }\end{array}$ \\
\hline Spotted by spotted & $\begin{array}{c}207 \\
\text { (30 litters) }\end{array}$ & 13 (5 litters) 10 & $\begin{array}{c}4 \\
\text { (1 litter) }\end{array}$ \\
\hline Spotted by solid & $\begin{array}{c}18 \\
\text { (3 litters) }\end{array}$ & ${ }^{49}(12 \text { litters })^{45}$ & $\begin{array}{c}13 \\
\text { (2 litters) }\end{array}$ \\
\hline Solid by solid & $\begin{array}{l}2 \text { (very small spots on } \\
\text { breast) } \\
\text { (1 litter) }\end{array}$ & & $\begin{array}{c}19 \\
\text { (2 litters) }\end{array}$ \\
\hline
\end{tabular}




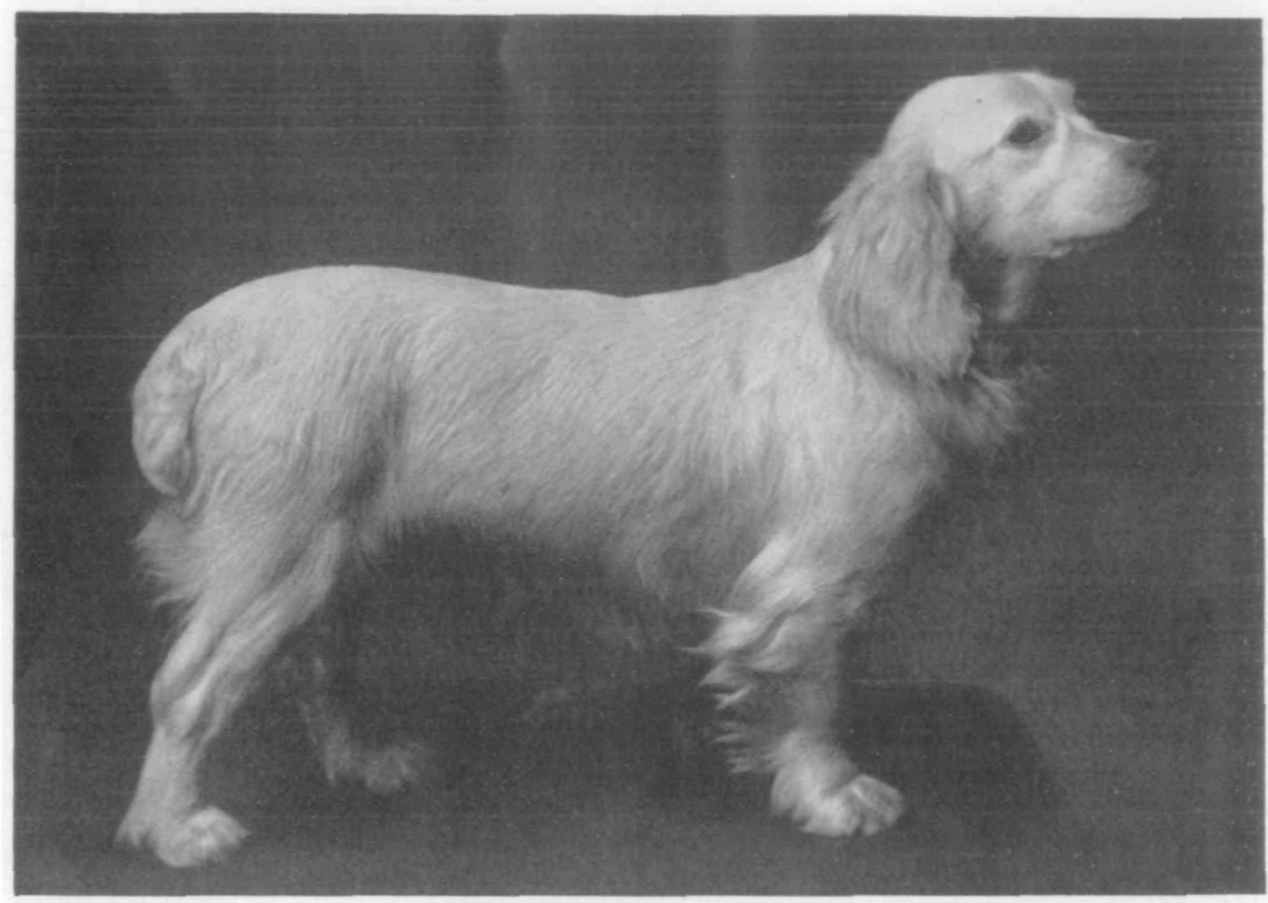

SIMCOE PURITY, A WHITE COCKER SPANIEL

A valuable "sport" in the breed is this dog, produced in the Simcoe kennels of F. E. Curtis, Simcoe, Ontario, Canada. He is the offspring of a solid black dog and a solid red bitch. The animal is not an albino, for his nose and foot-pads, as well as eyes, are dark in color. $\mathrm{He}$ is probably to be considered a dilute lemon. The value of inbreeding is well illustrated in a case like this: bred to outside females, Purity has produced no white pups, but when mated with his own close relatives a few pups in each litter are white. As a result, a pure white strain, hitherto unknown in the breed, might be established. (Fig. 6.)

in the table probably arise from the curious behavior of the spotting factor in different strains of dogs. If two individuals, which show small spots, coming from a solid color strain, are crossed, half of the resulting offspring are apt to be solid color, while the rest will be spotted. Selection for larger areas of white or color has a cumulative effect, which affects the ratio of spotted to solid offspring.

Another cause of apparent irregularities in the table arises from the fact that a dog showing a breast spot or white on the toes may be classed as a solid color in the kennel records. The two litters of thirteen solid color pups, shown in the last column of the table are from a tricolor mated with a spotted dog. The bicolor pattern factor, which will be described later, seems to have some effect in producing pups of solid color.

The second type of spotting, which we shall call bicolor spotting, ${ }^{3}$ is in reality due to a pattern factor which allows a lighter (hypostatic) color to show on certain definite parts of the body. For example the condition most frequently seen is that of a black dog having dark or light red or lemon spots over each eye, and extended red areas distributed on the sides of the muzzle, inside of the ear, posterior surfaces of the legs, and on the ventral sides of the chest, abdomen, and tail. This pattern is most striking when found on dogs showing much black, but it is commonly

See Pocock, R. I., 1907. On the Black-and-Tan Pattern of Domestic Dogs (Canis familiaris). Ann. Mag. Nat. Hist., Ser. 7. Vol. 19, pp. 192-194. 
met in animals of other colors. Liver colored dogs may be marked with red or lemon, red dogs with lemon. If white occurs along with the bicolor pattern the dog is usually described as tricolor.

The inheritance of this factor is indicated by the following observation: Three matings in which principals are not bicolors or tricolors, but have tricolors among their ancestors, yield twenty-one non-tricolors and three tricolors, as shown in the pedigree below. Among these noted as non-tricolor are probably some red bicolors. When tricolors are crossed with non-tricolors which come from strains not showing the bicolor or tricolor patterns there result only plain colored offspring. However in two cases where tricolors were crossed with non-tricolors from strains containing the tricolor factors there occurred seven non-tricolor and three tricolor offspring.

The bicolor factor is certainly recessive. Certain combinations should always produce tricolors. For example a tricolor of class 2 mated with a liver and white of class 5 which shows the buff marks should produce litters consisting exclusively of black tricolors. Several similar matings are possible, as can be seen from the table. We know of no such mating, but it should be an easy matter to test this hypothesis.

The tricolor markings with the hypostatic colors are limited, in the following breeds, to the same areas as in Cockers;
Dachshunde, Toy Black and Tans, Manchester Terriers, Gordon Setters, King Charles and Prince Charles Spaniels, some Fox Terriers, Pointers, Beagles and Collies. The combination of red with lemon marks is more often found in Collies than in any other breed.

In certain Fox Terriers and Beagles the tan extends further up on the legs, and over the face, until the black is limited to the ears, the upper part of the occiput, and over the back and sides. In the Welsh Terriers this distribution of color is the usual one. In the Airedale the black is limited to a saddle commencing at the withers and extending over the back, tail and sides. All of these markings are probably due to the same pattern factor which we call bicolor in Cockers.

This pedigree was sent to us by one of our cofrespondents, as an example of the absolutely unpredictable nature of the heredity of colors in Cocker Spaniels! The solid red parent is evidently of class 8 , while the liver and white parent is of class 6 . The presence of a tricolor pup, and the fact that approximately half of the pups were spotted makes the pedigree most interesting. We shall leave it to the reader to decide whether or not the results of this mating could have been predicted with fair accuracy.

In this mating the number of lemons is insufficient. One of those noted as red may be, in reality, a lemon. In our records lemon seems to occur less often

Liver and white

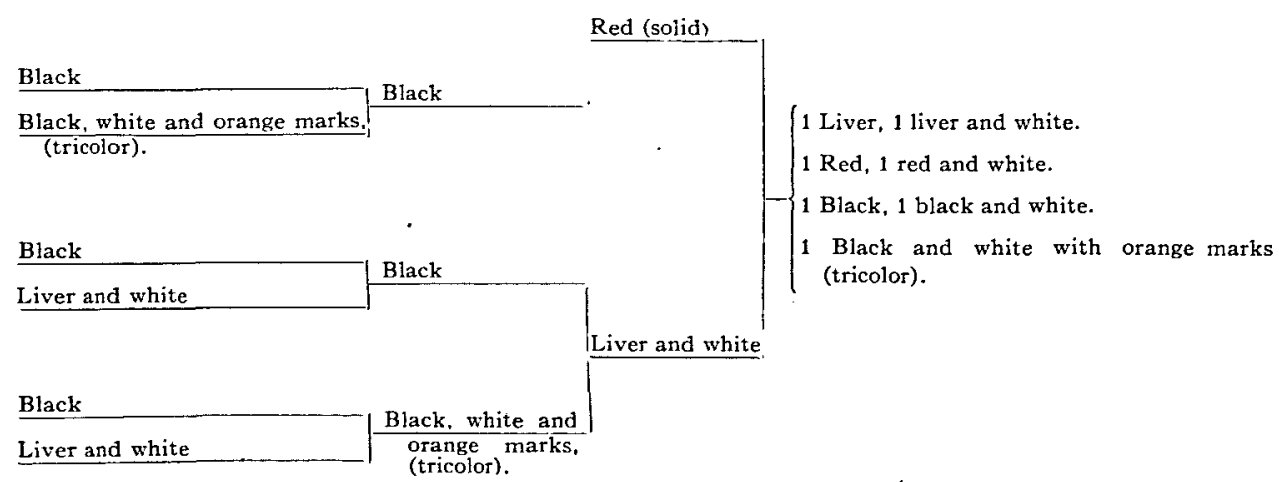


than it is expected. This lack could be explained by the hypothesis that the gametes containing be are not as active in the fertilization process as those which contain $\mathrm{B}$ or $\mathrm{E}$ or both.

\section{EYE, FOOT-PAD, AND NOSE COLORS}

While we do not have complete records of the eye, foot-pad and nose colors, there are a few general observations which it seems well to add here for the sake of calling attention to the association of these colors.

The eye colors of Cockers range from black through various shades of brown to yellow. The eye color is not necessarily correlated with the coat color, or the color of the nose and foot-pads, except in the case of liver colored individuals where the eye is usually not darker than the coat, and is commonly much lighter. A black or red dog may have black, brown or yellow eyes. As far as our records go they show that the darker colors are epistatic to the lighter ones.

The nose color is always the same as the color of the foot pads. Black dogs always have black noses, while red dogs may have black or brown noses and foot pads, and may also have black spots on the skin which are not associated with colored spots in the coat. Lemon colored dogs may have the nose and foot pads black, brown, or a dusky pink. Chocolate colored dogs always have chocolate nose and foot pads. It is clear that the red animal can produce black pigment in the skin and eye but not in the hair, while the chocolate or liver colored individual can produce no black either in the eye or skin.

\section{NEW PUBLICATIONS}

THE NEXT GENERATION, by Frederick A. Rhodes, Chairman of the Morals Efficiency Committee of Pittsburgh. Pp. 290, price $\$ 1.50$ net. Boston, Richard G. Badger, 1915.

Dr. Rhodes has attempted to test a great many social problems by the principles of biology, but his book bears the evidence of being hastily put together from newspaper articles, and is not likely to take rank as a serious contribution to eugenics. Although its scope and general attitude toward race betterment are admirable, the work is marred by a great many errors of fact, and a tendency to substitute quoted opinions of other people for reports of research. It is easy reading, however, and may lead students of the wide range of problems on which he touches to desire further knowledge of what biology has to offer them; in this case it will perform a real service.

\section{Improving the Chile Pepper}

The chile pepper (Capsicum annuum), so much relished by Mexicans, is the object of attention at the New Mexico Agricultural Experiment Station, where for the last five years it has been improved by selection for larger, smoother, fleshier pods and freedom from blight. Three good strains have been perpetuated from the fifteen with which the experiment started.

\section{Studies in Correlation}

Correlation is the principal concern of breeding studies, at the Montana Agricultural Experiment Station, the characters of plants being measured in comparison with those of their parents. Practical breeding of various cereals is also being done. 